\title{
Oryzalin-induced Tetraploidy in Cryptomeria japonica (Cupressaceae)
}

\author{
Ryan N. Contreras ${ }^{1}$ and John M. Ruter ${ }^{2,4}$ \\ Department of Horticulture, University of Georgia, Tifton Campus, 4604 \\ Research Way, Tifton, GA 31794
}

\author{
Brian M. Schwartz \\ Department of Crop and Soil Sciences, University of Georgia, Tifton \\ Campus, Tifton, GA 31793-0748
}

Additional index words. cytology, flow cytometry, gymnosperm, japanese-cedar

\begin{abstract}
Japanese-cedar [Cryptomeria japonica (L.f.) D. Don] represents an alternative to leyland cypress $[\times$ Cuprocyparis leylandii (A.B. Jacks. \& Dallim.) Farjon] as an evergreen screen or specimen plant for landscapes. It performs well under a range of soil and environmental conditions but has been underused attributable, in part, to unsightly winter browning caused by photoinhibition. In previous studies, chance seedlings that did not exhibit winter browning were identified as tetraploids. The current study was conducted to induce polyploidy in japanese-cedar. Approximately 600 seedlings were sprayed with $150 \mu M$ oryzalin $+0.1 \%$ SilEnergy $^{\top \mathrm{M}}$ for 30 consecutive days under laboratory conditions. Two hundred thirty-seven seedlings with thickened and twisted leaves were selected, transplanted, and grown in a glasshouse for $\mathbf{1 2 0}$ days. Seedling ploidy levels were analyzed using flow cytometry 180 days after treatment (DAT), identifying $197(83.1 \%)$ tetraploids, $22(9.3 \%)$ cytochimeras, and $18(7.6 \%)$ diploids. Morphology of induced tetraploids was similar to that previously described and provided a phenotypic marker during selection that was over $92 \%$ accurate. A random subset of 20 tetraploid individuals was analyzed 270 DAT and were found to contain only tetraploid cells in the leaves analyzed, confirming stability over this period. This study demonstrated the use of oryzalin for inducing tetraploids in japanese-cedar, which we predict will be effective in other gymnosperms.
\end{abstract}

Cryptomeria D. Don is a monotypic genus comprised of $C$. japonica and its two varieties, C. japonica var. japonica and C. japonica var. sinensis Miq. Cryptomeria is native to China (var. sinensis) and Japan (var. japonica) and is an important timber tree of the latter, reaching heights of 36 to $46 \mathrm{~m}$ in the wild (Dallimore and Jackson, 1967) but is typically 15 to $25 \mathrm{~m}$ in gardens (Tripp and Raulston, 1992).

Cryptomerias, also commonly called japanese-cedars or sugi, offer an alternative to leyland cypress due to their limited pest problems (Tripp, 1993; Tripp and Raulston, 1992), ability to perform well under the hot, humid conditions of the southeastern United States, and tolerance of heavy soils during

\footnotetext{
Received for publication 1 Oct. 2009. Accepted for publication 25 Nov. 2009.

We thank Amanda Webb, Nancy Hand, Bruce Tucker, and Brandon Coker for their technical assistance.

From a dissertation submitted by R.N.C. as partial fulfillment of the requirements for the Ph.D. degree.

${ }^{1}$ Graduate Research Assistant. Current appointment and address: Assistant Professor, Department of Horticulture, Oregon State University, Corvallis, OR 97331-7304

${ }^{2}$ Professor.

${ }^{3}$ Assistant Professor.

${ }^{4}$ To whom reprint requests should be addressed; e-mail ruter@uga.edu.
}

both wet and dry conditions (Tripp, 1993). Cultivars are numerous and varied and include forms that are dwarf, have irregular branching, and have varying foliage colors, including variegated (Rouse et al., 2000). However, in full sun, they exhibit browning in winter that can be undesirable (personal observation). Winter browning in japanesecedar occurs in sun-exposed leaves during periods of low temperature indicating that photoinhibition plays a role (Han and Mukai, 1999; Ida, 1981). Ida (1981) reported that chloroplasts in sun-exposed leaves were transformed into rhodoxanthin-containing chromoplasts during winter, resulting in the brown-red color.

In Japanese forestry nurseries, tetraploid forms of japanese-cedar have been identified based on their morphology (Chiba, 1951). Tetraploids have been shown to be more resistant to oxidative damage from ultraviolet light than diploids through increased antioxidant levels (Niwa and Sasaki, 2003). However, these seedlings have been rogued from nurseries based on their unfamiliar appearance (Chiba, 1951) and saplings that readily change needle color from green to brown or orange-yellow have been recommended as being superior individuals for silviculture (Han and Mukai, 1999). Negative selection has been imposed based on the lack of use of tetraploids in a silviculture, but they may have great potential for use in the nursery and landscape industries in the United States by providing nonbrowning forms that consumers find more attractive.

Polyploidy in gymnosperms is rare (Ahuja, 2005; Khoshoo, 1959, 1961), but following the work of Blakeslee and Avery (1937), there were a number of studies that attempted to induce polyploidy. The primarily goal of those studies was to develop more vigorous trees for timber production. Research included attempts to induce polyploidy in pines (Pinus L.) (Hyun, 1953; Mergen, 1959; Mirov and Stockwell, 1939), japanese cypress (Chamaecyparis obtusa Endl.) (Kanezawa, 1951), and giant sequoia [Sequoiadendron giganteum (Lindl.) J. Bucholz] (Jensen and Levan, 1941). These studies used a variety of delivery methods at various stages of development, including treatment of seeds, newly germinated seedlings, and shoot tips; however, all previous studies to induce polyploidy have used colchicine. Colchicine acts by disrupting the microtubular structure of dividing cells in both plants and animals (Bartels and Hilton, 1973). The mode of action of dinitroaniline herbicides such as oryzalin has also been determined (Bartels and Hilton, 1973; Upadhyaya and Noodén, 1977, 1980) and have been found to bind more specifically to plant tubulin in vitro than colchicine (Yemets and Blume, 2008). In addition to more specific binding, dinitroaniline herbicides have been found to be less toxic and to act at 100 (Yemets and Blume, 2008) to 1000 times (Upadhyaya and Noodén, 1977) lower concentrations than colchicine. As a result of the reduced toxicity and more effective binding, dinitroaniline herbicides such as oryzalin may be preferable for inducing polyploidy. The objective of the current study was to induce polyploidy in Cryptomeria japonica using oryzalin.

\section{Materials and Methods}

Plant material. Wild-collected seed from China of Cryptomeria japonica were received from Lawyer Nursery, Inc., Plains, MT. Based on the collection site, the seed used may have been $C$. japonica var. sinensis; however, this was not able to be confirmed. Approximately 1000 seeds were sown in germination trays containing 8 pine bark: 1 sand $(\mathrm{v} / \mathrm{v})$ amended with $0.91 \mathrm{~kg} \cdot \mathrm{m}^{-3}$ dolomitic lime and $0.45 \mathrm{~kg} \cdot \mathrm{m}^{-3}$ Micromax (The Scotts Co., Marysville, $\mathrm{OH}$ ) and allowed to germinate in a glasshouse with day/ night set temperatures of $27 / 20^{\circ} \mathrm{C}$. Approximately 600 seedlings germinated and were moved to the laboratory and grown under constant light $\left(28 \mu \mathrm{mol} \cdot \mathrm{m}^{-2} \cdot \mathrm{s}^{-1}\right)$ supplied by cool-white fluorescent lamps at $25^{\circ} \mathrm{C}$.

Cytology. Roots were harvested and pretreated for $24 \mathrm{~h}$ in $3 \mathrm{~mm}$ 8-hydroxyquinoline (Fisher Scientific, Suwanee, GA) $+0.24 \mathrm{~mm}$ cycloheximide (Acros Organics, Morris Plains, NJ) at $4{ }^{\circ} \mathrm{C}$. After pretreatment, roots were transferred to Carnoy's solution [6 100\% ethyl alcohol:3 chloroform:1 glacial acetic acid (by volume)] and fixed overnight at $25{ }^{\circ} \mathrm{C}$. Roots were rinsed with deionized water and transferred to aqueous $70 \%$ ethyl 
alcohol (v/v) and stored at $4{ }^{\circ} \mathrm{C}$ until observation. At the time of observation, roots were rinsed in deionized water for $30 \mathrm{~min}$ and root tips were excised on a glass slide using a razor. Root tips were then incubated at $37{ }^{\circ} \mathrm{C}$ in an enzyme mixture [0.5\% cellulase (Karlan Research, Torrance, CA), 0.5\% cytohelicase (Sigma-Aldrich Co., St. Louis, MO), and $0.5 \%$ pectolyase Y-23 (Karlan Research), in $50 \mathrm{~mm}$ citrate buffer at $\mathrm{pH} 4.5$ ] for $4.5 \mathrm{~h}$. After digestion, root tips were rinsed, transferred to a glass slide using a Pasteur pipette, and liquid removed by wicking with a one-ply tissue. Meristematic cells were separated from root cap and other nondividing cells by gently pressing the root tip with a dissecting probe. Before allowing cells to dry, a drop of modified carbol fuchsin stain (Kao, 1975) was added and cells were spread under a cover glass by applying even pressure. Slides were scanned at $\times 100$ magnification; counting and photomicrography were performed at $\times 1000$ magnification using a compound light microscope (Fisher Micromaster ${ }^{\circledR}$ I; Fisher Scientific). Chromosomes of five cells were counted.

Inducing polyploidy. Seedlings were sprayed to runoff daily for $30 \mathrm{~d}$ with an aqueous solution containing $150 \mu \mathrm{M}$ oryzalin (supplied as Surflan ${ }^{\circledR}$ AS; United Phosphorus, Trenton, NJ) $+0.1 \%$ SilEnergy $^{\mathrm{TM}}$ (Brewer International, Vero Beach, FL), an organosilicate surfactant, using a standard spray bottle (Model P-32; Sprayco, Farmington Hills, MI). The rate of oryzalin was selected based on several previous studies in other genera that induced polyploidy using 150 $\mu \mathrm{M}$ solutions (Contreras et al., 2007, 2009; Olsen et al., 2006). After $30 \mathrm{~d}, \approx 500$ surviving seedlings were moved to a glasshouse and transplanted into six trays containing the pine bark substrate described. Seedlings were allowed to grow for 4 months and then transplanted into 0.2-L containers filled with 1 Pro-Mix BX with Biofungicide (Premier Horticulture, Quakertown, PA):1 pine bark/ sand mixture described previously (v/v), and fertilized weekly at a rate of $100 \mathrm{ppm}$ nitrogen using TotalGro 20N-4.4P-17.6K watersoluble fertilizer (SDT Industries, Winnsboro, LA). Morphology indicative of polyploidy in japanese-cedar (Chiba, 1951) was used to select 237 seedlings for transplantation. After 1 month of growth [180 d after treatment (DAT)], the ploidy level of the seedlings was determined using flow cytometry.

Identification of polyploidy. Flow cytometry, as described in Contreras et al. (2009) with modifications, was conducted on the 237 selected seedlings with altered leaf morphology. Five plants were evaluated during each analysis by bulking leaves. For bulked samples, a comparable amount of mature leaf tissue from five plants was collected and analyzed. In bulked samples in which a single peak was observed, all plants were recorded as being composed solely of tissue at the ploidy level corresponding to the fluorescence channel. For bulked analyses in which there were multiple peaks, plants were analyzed individually to determine ploidy of

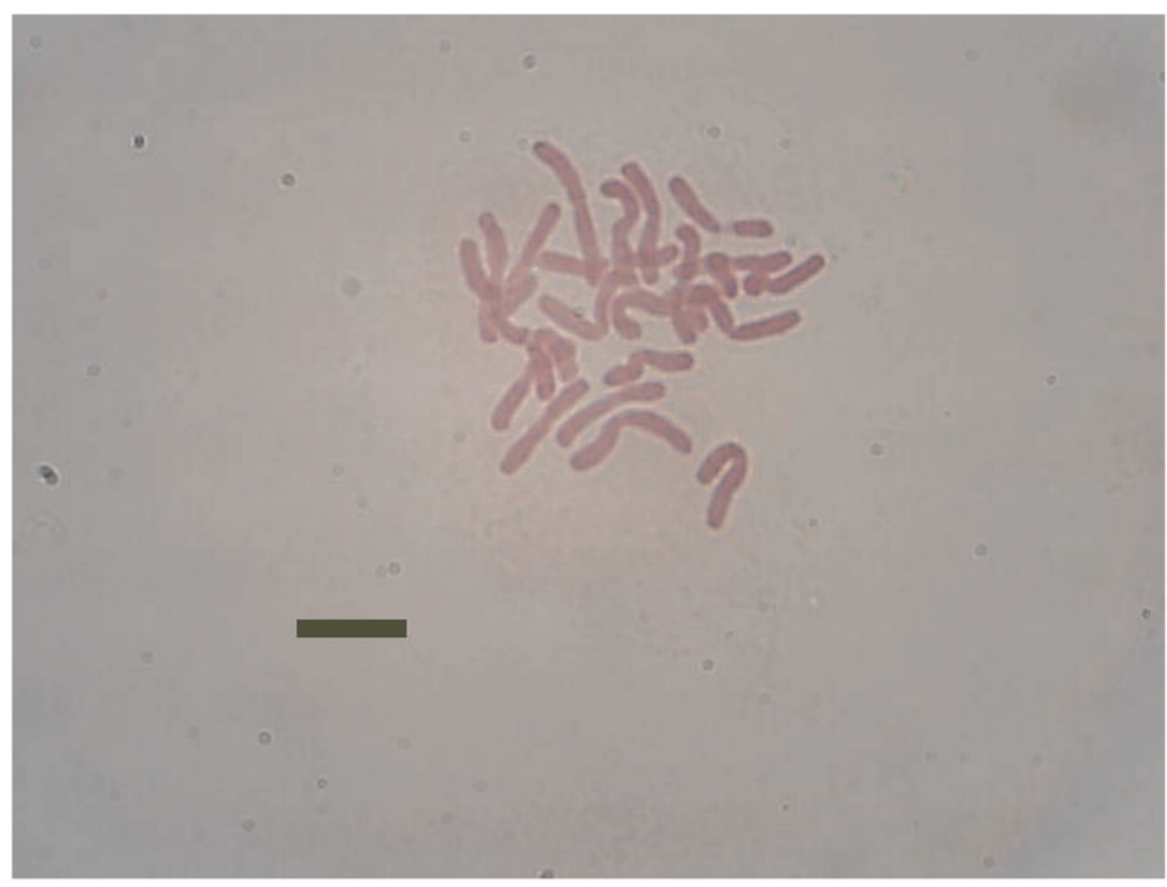

Fig. 1. Photomicrograph of a chromosome spread from a root tip squash of diploid $(2 n=2 x=22)$ Cryptomeria japonica taken at $\times 1000$ magnification. Scale bar $=10 \mu \mathrm{m}$.

individual plants. The channel corresponding to diploid mean relative DNA fluorescence (MRF) was determined based on an individual that was confirmed as diploid $(2 n=2 x=$ 22 ) using cytology as described previously. The diploid channel served as a standard for comparison with determined ploidy for most samples. In some cases, the peak was ambiguous as a result of peak shifting and ploidy level was not clear. These samples were analyzed individually using an internal standard [(Pisum sativum L. 'Ctirad'; $2 \mathrm{C}=$ $8.76 \mathrm{pg}$ ) (Greilhuber et al., 2007)]. The internal standard was used to calculate the $1 \mathrm{C}$ DNA content of the diploid [1C DNA $(\mathrm{pg})=$ $($ MRF sample/MRF standard) $\times 8.76 \mathrm{pg}) / 2$ )]. DNA content of the unknown samples was calculated and ploidy determined based on the $1 \mathrm{C}$ DNA content of the diploid. A random subset of 20 individuals identified as tetraploid 180 DAT was reanalyzed using flow cytometry 270 DAT to determine if they remained stable tetraploids.

\section{Results and Discussion}

Results from chromosome counts on Cryptomeria japonica revealed a diploid complement of $2 n=2 x=22$ (Fig. 1). This finding agrees with earlier results (Khoshoo, 1961; Sax and Sax, 1933). As a result of the large size and difficulty in spreading chromosomes, it was necessary to use the enzyme mixture described for digestion as opposed to a more standard $\mathrm{HCl}$ hydrolysis.

Treating $C$. japonica seedlings for 30 consecutive days with $150 \mu \mathrm{M}$ oryzalin + $0.1 \%$ SilEnergy ${ }^{\mathrm{TM}}$ successfully induced tetraploidy. Numerous preliminary experiments were unsuccessful in developing tetraploids, including soaking seeds in various rates of
Table 1. Results of treating Cryptomeria japonica seedling shoot tips with $150 \mu \mathrm{M}$ oryzalin + $0.1 \%$ SilEnergy ${ }^{\mathrm{TM}}$ for 30 consecutive days to induce tetraploids.

\begin{tabular}{lcc}
\hline Ploidy & No. of seedlings & Percent of total \\
\hline $2 x$ & 18 & 7.6 \\
$2 x+4 x$ & 22 & 9.3 \\
$4 x$ & 197 & 83.1 \\
Total $^{z}$ & 237 & 100 \\
\hline
\end{tabular}

zTwo hundred thirty-seven seedlings selected based on foliar morphology from $\approx 500$ surviving seedlings after beginning $30 \mathrm{~d}$ treatment on $\approx 600$ seedlings.

colchicine, germinating seeds in various rates of colchicine, and treatment of shoot tips of seedlings and stem cuttings (Contreras, 2009; Contreras and Ruter, 2008) with various rates of oryzalin. We hypothesized that previous applications of oryzalin were unsuccessful because they were too short ( 1 to $5 \mathrm{~d}$ ) and did not contain a surfactant to penetrate the cuticle. A total of 237 seedlings was analyzed using flow cytometry and of these, 219 $(92.4 \%)$ contained tetraploid cells (Table 1$)$. Flow cytometric analysis of seedlings revealed $197(83.1 \%)$ tetraploids, $22(9.3 \%)$ cytochimeras, and 18 (7.6\%) diploids (Table 1; Fig. 2). Morphology of induced tetraploids (Fig. 3), primarily thickened and twisted leaves, was similar to that previously described (Chiba, 1951) and provided a phenotypic marker for selection during transplantation that was over $92 \%$ accurate. Tetraploids had thicker leaves, but leaf length and growth rate displayed variation typical of a seedling population. Other populations grown from the same seed source had no individuals that exhibited leaf morphology indicative of polyploidy (personal observation), which provides strong indication that 

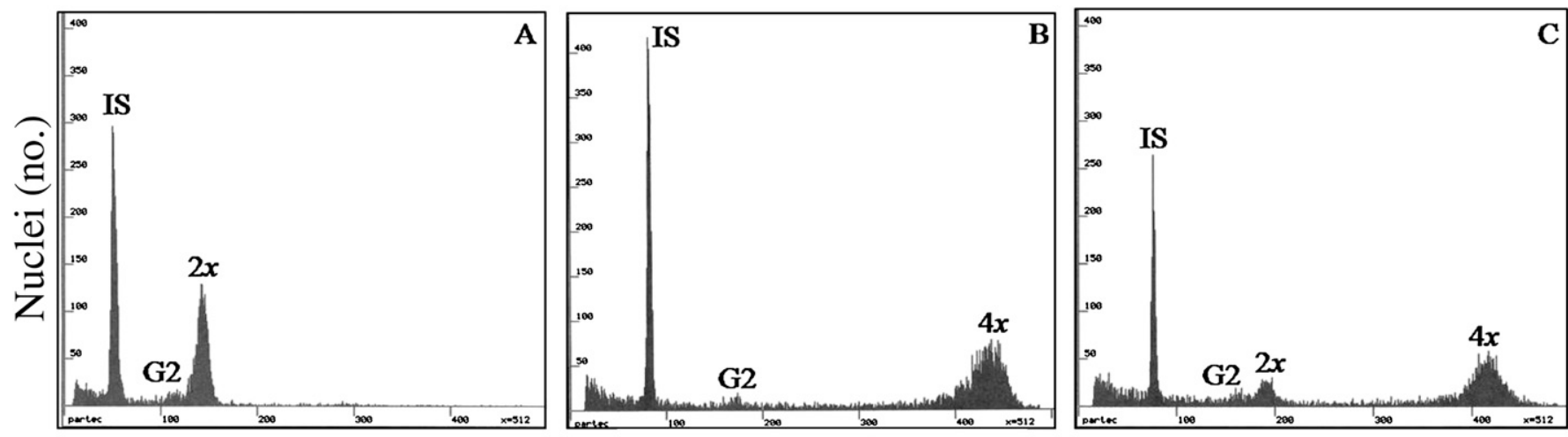

\section{Relative DNA fluorescence}

Fig. 2. Representative histograms generated by analyzing leaves of Cryptomeria japonica from seedlings treated for 30 consecutive days with $150 \mu \mathrm{M}$ oryzalin + $0.1 \%$ SilEnergy ${ }^{\top \mathrm{TM}}$ using flow cytometry for diploid $(2 x)(\mathbf{A})$, tetraploid $(4 x)(\mathbf{B})$, and mixoploid $(2 x+4 x)(\mathbf{C})$. (A) Internal standard (IS; Pisum sativum 'Ctirad') mean relative fluorescence $(\mathrm{MRF})=52, \mathrm{G} 2$ peak from cell cycling of IS, and $2 x \mathrm{MRF}=143 ;(\mathbf{B}) \mathrm{IS} \mathrm{MRF}=83$ and $4 x \mathrm{MRF}=437 ;(\mathbf{C}) \mathrm{IS} \mathrm{MRF}=77,2 x \mathrm{MRF}=$ $191,4 x \mathrm{MRF}=416$

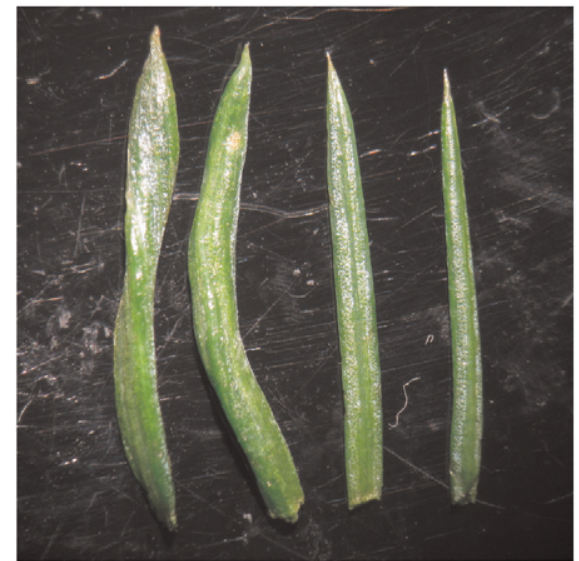

Fig. 3. Two leaves from an induced tetraploid of Cryptomeria japonica (left) exhibiting thickened and twisted morphology and two leaves of diploid (right) with wild-type phenotype.

the tetraploids recovered were the result of the treatment and not chance seedlings. Also, Chiba (1951) reported that recovery of polyploids as chance seedlings was several orders of magnitude lower $(0.0005 \%)$ than observed in the current report.

Compared with the number of studies on induced polyploidy in angiosperms, there have been few in gymnosperms and no reports of induced polyploidy in japanesecedar (Ahuja, 2005). This is the first study reporting the use of oryzalin as a mitotic inhibitor to induce polyploidy in a gymnosperm. Previous studies on gymnosperms used colchicine to treat seed (Hyun, 1953; Jensen and Levan, 1941; Kanezawa, 1951; Mirov and Stockwell, 1939), shoot tips of seedlings (Hyun, 1953), or injection into vascular tissue (Jensen and Levan, 1941). Jensen and Levan (1941) induced polyploidy in Sequoia gigantea (Lindl.) Decne. (= Sequoiadendron giganteum) by germinating seeds on filter paper moistened with $0.1 \%$ and $0.2 \%$ colchicine. Polyploidy was confirmed through chromosome counts in a plant from the $0.2 \%$ treatment and $25 \%$ of $S$. gigantea plants treated with $0.1 \%$ exhibited a phenotype indicative of polyploidy (Jensen and Levan, 1941). Hyun (1953) reported on numerous studies to induce polyploidy in pines but had greatest success by treating seeds of Pinus ponderosa Douglas ex Loudon with $0.2 \%$ colchicine for 4 or $6 \mathrm{~d}$ and seeds of $P$. $\times$ attenuradiata Stockw. \& Righter with $0.2 \%$ colchicine for $4 \mathrm{~d}$. Treatment of shoot tips of $P$. ponderosa, $P$. jeffreyi Balf., and $P$. $\times$ attenuradiata seedlings produced cytochimeras but no stable tetraploids (Hyun, 1953). Kanezawa (1951) obtained an induced tetraploid of Chamaecyparis obtusa by soaking seeds in $0.3 \%$ colchicine for $24 \mathrm{~h}$ and then treating seedlings with the same solution every 2 or $3 \mathrm{~d}$ over a period of $20 \mathrm{~d}$.

Plants were initially evaluated using flow cytometry 180 DAT and then a random subset of 20 tetraploid plants was reassessed 270 DAT, which were all found to contain only tetraploid cells. Hyun (1953) reported some reversion of cytochimeras to diploids; however, most polyploids remained stable over 1 year after treatment. Johnsson (1975) reported that colchicine-induced tetraploids of Pinus sylvestris L., Larix sibirica Ledeb., and Picea abies (L.) H. Karst. contained only tetraploid cells 30 years after polyploid induction. It appears that if induction of polyploidy is successful and the resulting individual contains only polyploid cells (it is not a cytochimera) that it is likely to remain stable over time. However, continued evaluation of the induced tetraploids in the current study will be required to determine long-term stability. Furthermore, because shoot tips were treated, the roots of individuals with tetraploid leaves are presumed to be diploid. Therefore, to obtain plants with only tetraploid cells, tetraploids will be propagated by stem cuttings when sufficient material is available.

This research demonstrates that oryzalin is effective in developing tetraploids in japanese-cedar and we predict that similar treatments may be effective in other gymnosperms. Applying $150 \mu \mathrm{M}$ oryzalin $+0.1 \%$ SilEnergy ${ }^{\mathrm{TM}}$ for $30 \mathrm{~d}$ using a spray bottle along with selection based on phenotype resulted in a high percentage of induced tetraploids. Long-term evaluation will be conducted at multiple sites to determine if tetraploids remain stable over time and to evaluate their growth and ornamental potential.

\section{Literature Cited}

Ahuja, M.R. 2005. Polyploidy in gymnosperms: Revisited. Silvae Genet. 54:59-69.

Bartels, P.G. and J.L. Hilton. 1973. Comparison of trifluralin, oryzalin, pronamide, propham, and colchicine treatments on microtubules. Pestic. Biochem. Physiol. 3:462-472.

Blakeslee, A.F. and A.G. Avery. 1937. Methods of inducing doubling of chromosomes in plants: By treatment with colchicine. J. Hered. 28: 393-411.

Chiba, S. 1951. Triploids and tetraploids of sugi (Cryptomeria japonica D. Don) selected in the forest nursery. Bul. Govt. For. Expt. Sta. (Tokyo) 49:99-109.

Contreras, R.N. 2009. Interspecific hybridization, ploidy manipulation, and cytological and genetic analyses as tools for breeding and improvement of Callicarpa L., Cryptomeria D. Don, Hibiscus L., and Tecoma Juss. Univ. Ga., Athens, PhD Diss.

Contreras, R.N. and J.M. Ruter. 2008. Preliminary efforts to induce polyploidy in Cryptomeria japonica. Proc. 53rd Ann. SNA Res. Conf. 53:159-161

Contreras, R.N., J.M. Ruter, and W.W. Hanna. 2009. An oryzalin-induced autoallooctoploid of Hibiscus acetosella Welw. ex Hiern. 'Panama Red' (Malvaceae). J. Amer. Soc. Hort. Sci. 134:553-559.

Contreras, R.N., T.G. Ranney, and S.P. Tallury. 2007. Reproductive behavior of diploid and allotetraploid Rhododendron L. 'Fragrant Affinity'. HortScience 42:31-34.

Dallimore, W. and A.B. Jackson. 1967. A handbook of coniferae and ginkgoaceae. 4th Ed. St. Martin's Press, New York, NY.

Greilhuber, J., E.M. Temsch, and J.M. Loureiro. 2007. Nuclear DNA content measurement, p. 67-101. In: Doležel, J., J. Greilhuber, and J. Suda (eds.). Flow cytometery with plant cells: 
Analysis of genes, chromosomes and genomes. Wiley-VCH, Weinheim, Germany.

Han, Q. and Y. Mukai. 1999. Cold acclimation and photoinhibition of photosynthesis accompanied by needle color changes in Cryptomeria japonica during the winter. J. For. Res. 4:229234.

Hyun, S.K. 1953. Induction of polyploidy in pines by means of colchicine treatment. Z. Forstgenetik 3:25-33.

Ida, K. 1981. Eco-physiological studies on the response of taxodiaceous conifers to shading, with special reference to the behaviour of leaf pigments. I. Distribution of carotenoids in green and autumnal reddish brown leaves of gymnosperms. Bot. Mag. Tokyo 94:41-54.

Jensen, H. and A. Levan. 1941. Colchicine-induced tetraploidy in Sequoia gigantea [sic]. Hereditas 27:220-224.

Johnsson, H. 1975. Observations on induced polyploidy in some conifers. Silvae Genet. 24:6268

Kao, K.N. 1975. A nuclear staining method for plant protoplasts, p. 60-62. In: Gamborg, O.L. and L.R. Wetter (eds.). Plant tissue culture methods. Natl. Res. Council of Canada, Ottawa, Ontario, Canada.

Kanezawa, R. 1951. Induced tetraploidy in Japanese cypress (Chamaecyparis obtusa Endl.). Bul. of the Tokyo Univ. For. 39:21-30.

Khoshoo, T.N. 1959. Polyploidy in gymnosperms. Evolution 13:24-39.

Khoshoo, T.N. 1961. Chromosome numbers in gymnosperms. Silvae Genet. 10:1-9.

Mergen, F. 1959. Colchicine-induced polyploidy in pines. J. For. 57:180-190.

Mirov, N.T. and P. Stockwell. 1939. Colchicine treatment of pine seeds. J. Hered. 30:389-390.

Niwa, Y. and Y. Sasaki. 2003. Plant self-defense mechanisms against oxidative injury and protection of the forest by planting trees of triploids and tetraploids. Ecotoxicol. Environ. Saf. 55:70-81.

Olsen, R.T., T.G. Ranney, and D.J. Werner. 2006. Fertility and inheritance of variegated and purple foliage across polyploid series in Hypericum androsaemum L. J. Amer. Soc. Hort. Sci. 131:725-730.

Rouse, R.J., P.R. Fantz, and T.E. Bilderback. 2000. Descriptions and a key to cultivars of japanese- cedar cultivated in the eastern United States. HortTechnology 10:252-266.

Sax, K. and H.J. Sax. 1933. Chromosome number and morphology in the conifers. J. Arnold Arbor. 14:356-375.

Tripp, K.E. 1993. Sugi: The ancient japanese cedar finds new life in a profusion of outstanding cultivar forms. Amer. Nurseryman 178:26-39.

Tripp, K.E. and J.C. Raulston. 1992. Cryptomeria evaluations at the NCSU Arboretum. Proc. 37th Ann. Southern Nurs. Assoc. Res. Conf. 37: 336-339.

Upadhyaya, M.K. and L.D. Noodén. 1977. Mode of dinitroaniline herbicide action. I. Analysis of the colchicine-like effects of dinitroaniline herbicides. Plant Cell Physiol. 18:13191330 .

Upadhyaya, M.K. and L.D. Noodén. 1980. Mode of dinitroaniline herbicide action. II. Characterization of $\left[{ }^{14} \mathrm{C}\right]$ oryzalin uptake and binding. Plant Physiol. 66:1048-1052.

Yemets, A.I. and Y.B. Blume. 2008. Progress in plant polyploidization based on antimicrotubular drugs. The Open Hort. J. 1:15-20. 